University of Nebraska - Lincoln

DigitalCommons@University of Nebraska - Lincoln

Entomology Papers from Other Sources

Entomology Collections, Miscellaneous

1998

Oviposition Response of Cotesia plutellae (Hymenoptera:

Braconidae) to Sterile and Normal Diamondback Moth (Lepidoptera: Plutellidae) Larvae

\author{
J. S. Okine \\ Center for Medical, Agricultural, and Veterinary Entomology, USDA-ARS, 1700 S.W. 23rd Drive, Gainesville, \\ FL.32608 \\ E. R. Mitchell \\ Center for Medical, Agricultural, and Veterinary Entomology, USDA-ARS, 1700 S.W. 23rd Drive, Gainesville, \\ FL .32608 \\ J. Carpenter \\ Center for Medical, Agricultural, and Veterinary Entomology, USDA-ARS, 1700 S.W. 23rd Drive, Gainesville, \\ $F L .32608$ \\ C. Y. Hu \\ Center for Medical, Agricultural, and Veterinary Entomology, USDA-ARS, 1700 S.W. 23rd Drive, Gainesville, \\ FL.32608
}

Follow this and additional works at: https://digitalcommons.unl.edu/entomologyother

Part of the Entomology Commons

Okine, J. S.; Mitchell, E. R.; Carpenter, J.; and Hu, C. Y., "Oviposition Response of Cotesia plutellae (Hymenoptera: Braconidae) to Sterile and Normal Diamondback Moth (Lepidoptera: Plutellidae) Larvae" (1998). Entomology Papers from Other Sources. 107.

https://digitalcommons.unl.edu/entomologyother/107

This Article is brought to you for free and open access by the Entomology Collections, Miscellaneous at DigitalCommons@University of Nebraska - Lincoln. It has been accepted for inclusion in Entomology Papers from Other Sources by an authorized administrator of DigitalCommons@University of Nebraska - Lincoln. 
Biological ConTrol

\title{
Oviposition Response of Cotesia plutellae (Hymenoptera: Braconidae) to Sterile and Normal Diamondback Moth (Lepidoptera: Plutellidae) Larvae
}

\author{
J. S. OKINE, ${ }^{1}$ E. R. MITCHELL, J. CARPENTER, ${ }^{2}$ AND G. Y. Hu ${ }^{1}$
}

Center for Medical, Agricultural, and Veterinary Entomology, USDA-ARS, 1700 S.W. 23rd Drive, Gainesville, FL 32608

\begin{abstract}
Environ. Entomol. 27(6): 1520-1524 (1998)
ABSTRACT Augmentative release of the endoparasitoid Cotesia plutellae (Kurdjumov) to control diamondback moth, Plutella xylostella (L.), in cabbage, Brassica oleracea variety capitata (L.), would be expensive for growers if done continually during a growing season. A method for establishing released parasitoids would be very beneficial in the control of this pest. One method under consideration is to use sterile diamondback moth larvae deposited on 'nursery' collard plants as hosts for C. plutellae to allow the parasitoid to build up in numbers and spread into adjacent cabbage fields. Therefore, the ability of $C$. plutellae to accept and develop successfully in normal and sterile diamondback larvae was evaluated. C. plutellae does not discriminate between normal larvae and larvae from parents sterilized by gamma radiation, and both sets of larvae served as suitable hosts for the parasitoid. Parasitism, foliage consumption, and survivorship were similar for the 2 types of larvae. Adult female $F_{1}$ parasitoids developed from sterile diamondback larvae were as fit as those from normal larvae. In laboratory bioassays, sterile and normal diamondback larvae traversed similar distances before pupation. Field cage assays showed less distance traversed by both types of larvae compared with the laboratory studies. Survivorship for both types of larvae was very low under field conditions. Results indicate that sterile diamondback moth larvae are acceptable hosts for C. plutellae and suggest that the nursery approach toward establishment and build up of numbers would be a viable approach to in-field production of the parasitoid with little chance for harm to nearby cabbage because of spread of sterile larvae from the nursery plants. This approach could be a cost effective way to augment naturally occurring parasitoids and predators in diamondback moth management programs.
\end{abstract}

KEY WORDS Plutella xylostella, parasitoid, biological control, cabbage, insect pest management, spatial dispersion

THE DIAMONDBACK MOTH, Plutellae xylostella (L.), attacks brassicaceous-cruciferous crops worldwide, with annual control costs estimated at U.S. $\$ 1$ billion (Talekar et al. 1986, Talekar and Shelton 1993). In Florida, serious economic damage results from their attack of cabbage (Brassica oleracea variety capitata) (Jansson and Lecrone 1988). Diamondback moth attacks cabbage from seedling to harvest stage, reducing yield quantity and quality. Plants tolerate varying amounts of damage depending on the maturity of the plant (Mahr et al. 1993); seedlings are generally much more susceptible to damage. Indigenous parasitoid populations are at low densities at the seedling stage and do not readily control early season populations of diamondback moth. Consequently, growers must resort to the use of chemicals to achieve diamondback moth control.

The development of resistance in diamondback moths to all major groups of insecticides, including insect growth regulators and Bacillus thuringensis ssp.

\footnotetext{
${ }^{1}$ Department of Entomology and Nematology, University of Florida, Gainesville, FL 32611

${ }^{2}$ USDA-ARS, Tifton, GA.
}

kurstaki, is widespread (Sun et al. 1978, Miyata et al. 1982, Sun et al. 1986, Tabashnik et al. 1990, Shelton and Wyman 1992, Talekar and Shelton 1993, Tabashnik 1994). Insecticide resistance, destruction of beneficial insects, and environmental pollution from synthetic pesticides makes it important to evaluate alternative or improved management methods for diamondback moth control (Ooi and Sudderuddin 1978).

Proposed integrated pest management (IPM) strategies for diamondback moth include biological, chemical, and cultural control methods (Lim 1986, Waterhouse and Norris 1987, Biever et al. 1994). Cotesia plutellae (Kurdjumov) and Diadegma insulare (Cress) are 2 parasitoids used in diamondback moth control, with C. plutellae considered less effective than $D$. insulare (Parker 1971, Ru and Workman 1979, Horn 1987, Muckenfuss et al. 1992, Mitchell et al. 1997). Despite this, C. plutellae is a good candidate for augmentative control of diamondback moth because a mass-rearing technology has been developed for it; whereas, $D$. insulare is presently more difficult to mass rear.

The USDA-ARS has conducted field trials in Bunnell, Flagler County, FL, to evaluate the efficacy of a 
combination of control strategies including pheromones, trap cropping and augmentative release of $C$. plutellae to control diamondback moth in cabbage. To enhance the build up of released parasitoids in or near cabbage fields, a reservoir of diamondback moth larvae could be established on separate plantings of collard, Brassica oleracea variety ocephala (L.), just before the augmentative release of this parasitoid. This reservoir of diamondback moth larvae would preferentially be sterile. Sterility can be induced in larvae of the diamondback moth by exposing parent moths to substerilizing doses of gamma radiation (Sutrisno and Hoedaya 1993).

In this study we evaluated the suitability of sterile diamondback moth larvae as hosts, in terms of number of parasitoid progeny that successfully developed from the sterile and normal larvae when exposed to $C$. plutellae, and the fecundity of parasitoid $\mathrm{F}_{1}$ offspring developed in sterile larvae. We also measured the distance moved by diamondback moth larvae under both laboratory and field conditions.

\section{Materials and Methods}

Normal Larvae. Diamondback moth larvae used were reared at the USDA-ARS facilities in Gainesville, FL, on modified pinto bean diet as described by Guy et al. (1985). The colony was 13 mo old.

Sterile Diamondback Moth Larvae. Sterile diamondback moth larvae were produced from the laboratory colony at the USDA facility in Tifton, GA, which originated from the Gainesville, FL, colony. To obtain sterile eggs, larvae were sexed and reared separately on $300 \mathrm{ml}$ meridic diet in plastic boxes ( 20 by 20 by $8 \mathrm{~cm}$ ) (Burton and Perkins 1989). Male moths $(<24 \mathrm{~h}$ old $)$ were exposed to $150 \mathrm{~Gy}$ radiation at $20^{\circ} \mathrm{C}$ using a well-type ${ }^{60}$ Co source (Gammarad irradiator, model GR-12, U.S. Nuclear Division, Irvine, CA) delivering $\approx 46 \mathrm{~Gy} / \mathrm{min} \pm 5 \%$ (X-ray monitor probe calibration). Unirradiated virgin females were mated with irradiated males in Plexiglas cages. Grooved aluminum foils ( 12 by $12 \mathrm{~cm}$ ) dipped in cabbage extract and air dried served as oviposition substrates. The egg foils were stored in a cooled Styrofoam container and shipped overnight to the USDA-ARS facilities in Gainesville, FL. The sterile larvae were cultured as described for the nonsterile larvae. All the larvae were maintained at a photoperiod of 14:10 (L:D) h, $22 \pm$ $1^{\circ} \mathrm{C}$, and $40-50 \% \mathrm{RH}$.

Parasitoid Rearing. C. plutellae (2-3 d old) were allowed to oviposit into diamondback moth 2 nd instars. Parasitoid cocoons were placed in emergence cages in the absence of hosts or plants, so that the eclosing adults were unexposed to host or plant kairomones. Food, in the form of smeared honey and water soaked cotton balls, was provided for eclosing parasitoids.

Bioassays. Oviposition Response of C. plutellae to Sterile and Normal Diamondback Moth Larvae. The acceptability and suitability of sterile diamondback moth larvae as hosts for C. plutellae were examined. Five individually potted collard plants were each in- fested with either 20 normal or sterile 2 nd instars. Collard plants are the preferred alternative host of diamondback moth. The plants each had 5-9 leaves. Larval transfers were done in an outdoor screened field cage $(2.7$ by $2.3 \mathrm{~m}$ ) and infested plants were randomly arranged $30 \mathrm{~cm}$ apart in the cage and left for $6 \mathrm{~h}$ to allow larvae to acclimatize. After acclimatization, larvae were recounted and missing larvae replaced so that each plant harbored 20 larvae. Twentyfive mating pairs of $C$. plutellae $(3 \mathrm{~d}$ old) were introduced into the cage for $48 \mathrm{~h}$. Honey smeared on plastic petri dishes and water soaked cotton balls were provided for the parasitoids. After the 48-h oviposition period, larvae were counted, collected, and brought into the laboratory, where they were allowed to complete development. Foliage consumption was estimated by measuring leaf area consumed with a plastic $\mathrm{mm}^{2}$ grid (Okine et al. 1996).

In the laboratory, larvae from each treatment were put into separate Plexiglas cages ( 25 by 25 by $25 \mathrm{~cm}$ ) and held at $21 \pm 3^{\circ} \mathrm{C}, 50-60 \% \mathrm{RH}$, and a photoperiod of 12:12 [L:D] h. The larvae were fed fresh collard leaves every $2 \mathrm{~d}$ until pupation of diamondback moth or C. plutellae. Mortality and proportion parasitized were recorded. Dead larvae were dissected to check for encapsulated parasitoids. There were 5 replicates per treatment, and the experiment was repeated 5 times.

Measurement of Leaf Consumption. The total amount of foliage consumed by diamondback moth larvae from hatching to pupation was estimated by transferring 20 newly hatched sterile and normal larvae onto individual potted collard plants that were maintained within the field cage. Foliage consumption was calculated using a $\mathrm{mm}^{2}$ plastic grid under a dissecting microscope (Okine et al. 1996). This was repeated 10 times.

Evaluating Emergence Rate and Fitness of $F_{1}$ Parasitoids. Preeclosion time, percent eclosion, and sex ratio of parasitoids that developed from normal or sterile hosts were compared.

Fitness was determined in the following manner: 3 $F_{1}$ mated C. plutellae females from sterile and normal hosts were allowed to oviposit for $24 \mathrm{~h}$ into 20 late 2 nd instars maintained on pinto bean diet in a modified paper cup. The proportion parasitized was obtained by counting the number of parasitoid pupae that developed. Parasitoid pupae obtained were allowed to eclose and adults emerging were sexed. This was repeated 10 times for each type of larvae.

Dispersal Pattern and Survival of Diamondback Moth Larvae in the Laboratory. The potential of sterile and normal diamondback moth larvae to migrate onto cabbage from collard plants was investigated. This was evaluated by measuring the local movement of diamondback moth larvae from hatch to pupation under laboratory and field conditions. Survival was calculated by dividing the number of pupae obtained by the initial egg number. Under laboratory conditions, a sheet of diamondback moth eggs was attached to the outermost leaf of a potted collard plant, and this plant was placed adjacent to 3 other collard plants to 
form a continuum of leaves spanning $45-57 \mathrm{~cm}$. Both sterile and nonsterile larvae were tested. The farthest distance moved by an individual larva was measured and recorded at 2-d intervals until pupation. The number of larvae that spun down on silk or fell from the plants were recorded. Percent survival also was determined. The trial was repeated 5 times for each type of larvae.

Dispersal and Survival in Field Cage Trials. Collard transplants were planted $50 \mathrm{~cm}$ apart in rows. The rows were separated by $105 \mathrm{~cm}$. Three rows of plants, each with 22 plants per row, were enclosed within a fine mesh nylon screen supported by metal frames. One hundred sterile and normal larvae were used for each trial. The outermost leaf on each row was used as the point of infestation. The collard plants and larvae were monitored as described for the laboratory trial. This was repeated 2 times.

Data Analysis. Proportions of host parasitized per treatment were transformed by the arcsine transformation before analysis of variance (ANOVA) testing (SAS Institute 1988).

\section{Results}

Oviposition Response. There was no significant difference in proportion parasitism $(F=0.17, \mathrm{df}=1,9$; $P=0.689)$ between sterile larvae $(37.6 \pm 1.72 \%$ $[$ mean $\pm \mathrm{SE}])$ and normal larvae $(38.0 \pm 1.38 \%)$. The proportion of larvae that survived did not differ significantly between the 2 groups for the 48 -h period $(F=0.24, \mathrm{df}=1,9 ; P=0.636)$. Mortality was $<10 \%$ per pot for both types of larvae. None of the dissected dead larvae contained an encapsulated parasitoid.

Foliage Consumption. Larval leaf consumption did not differ between sterile and normal larvae during the 48 - $\mathrm{h}$ stinging period $(F=0.16, \mathrm{df}=1,49 ; P=$ 0.997 ). Sterile larvae consumed $60 \pm 0.68 \mathrm{~mm}^{2}$ and normal larvae consumed $59 \pm 4.7 \mathrm{~mm}^{2}$.

Leaf consumption from hatch to pupation in insects unexposed to $C$. plutellae was significantly different between types of larvae $(F=22.92, \mathrm{df}=1,19 ; F<$ $0.001)$. Sterile larvae consumed less foliage $(387.9 \pm$ $\left.15.74 \mathrm{~mm}^{2}\right)$ than the normal larvae $(475.3 \pm 14.7$ $\mathrm{mm}^{2}$ ). Mortality of sterile larvae was significantly higher compared with normal larvae $45 \pm 5.8 \%$ versus $33.5 \pm 7.4 \%(F=31.17, \mathrm{df}=1,19 ; P<0.001)$.

Emergence Rate and Fitness of $F_{1}$ Parasitoids. The period of development from hatch to pupation was $15 \mathrm{~d}$ for both types of larvae. The preeclosion time for C. plutellae pupae in both sets of larvae was $4 \mathrm{~d}$, and percent adult emergence was $80.5 \pm 8.8 \%$ for sterile larvae and $79.2 \pm 6.3 \%$ for normal larvae $(F=0.28, \mathrm{df}=$ 1,$9 ; P=0.611$ ). The sex ratio was 1.4:1 (females:males) for sterile larvae and 1.1:1 (females:males) for normal larvae. Percent parasitism obtained from $\mathrm{F}_{1}$ C. plutellae was not significantly different between sterile and nonsterile larvae $(F=0.11$, df $=1,19 ; P=0.741)$.

Dispersal Pattern and Survivability of Diamondback Moth Larvae. Under laboratory conditions the distance moved from point of egg attachment until pupation was not significantly different between ster- ile and normal larvae $(F=0.16, \mathrm{df}=1,9 ; P=0.997)$ under laboratory conditions. The maximum movement was $14 \pm 1.7 \mathrm{~cm}$ and $12 \pm 1.3 \mathrm{~cm}$ for sterile and normal larvae, respectively. Percent survival was not significantly different between normal $(47 \pm 1.2 \%)$ and sterile $(43 \pm 1.3 \%)$ larvae $(F=0.28, \mathrm{df}=1,8 ; P=$ 0.611).

Under field conditions, the distance moved by sterile and normal larvae was $9 \pm 1.3 \mathrm{~cm}$ and $13 \pm 1.6 \mathrm{~cm}$, respectively. Percent survival was $6 \pm 1.0 \%$ and $15 \pm$ $1.3 \%$ for sterile and normal larvae.

\section{Discussion}

The absence of a significant difference in parasitization indicates that sterile and normal larvae of the diamondback moth are equally acceptable to C. plutellae parasitoids. Both provided adequate nutritional and physiological conditions for parasitoid development. The success of the sterile larvae as host depended on their ability to attract and sustain parasitoid development within them. Host selection is a critical factor in biological control influencing fecundity (Hagvar and Hofsvang 1991). Sterile larvae apparently satisfied the nutritional and physiological requirements needed for growth and development of the parasitoid (Sequeira and Mackauer 1993). This similarity in parasitization of sterile and normal larvae also has been reported for C. marginiventris in Spodoptera exigua (Hübner) (Carpenter et al. 1996).

The relatively low percent parasitism obtained even under caged conditions is consistent with the levels of parasitism reported by Alam (1992), Wakisaka et al. (1992) and Mitchell et al. (1997) for C. plutellae. Despite the reported low parasitism rate, C. plutellae is considered the most promising parasitoid in the Oceanic Pacific region (Waterhouse and Norris 1987). Success of an augmentative release of a natural enemy is strongly influenced by the density of the host population at the time of release (Knipling 1992). C. plutellae displays highly density-dependent mortality, and parasitism levels rise with an increase in diamondback moth populations (Alam 1992). This quality could prove problematic if IPM works, because pest populations would be low and might not be able to sustain the parasitoid population as reported by Mitchell et al. (1997).

The similarity in foliage consumption during the 48-h stinging period is important because feeding produces chemicals that are used by natural enemies to locate prey (Dicke et al. 1990; Turlings et al. 1990, 1991; Dicke and Tokabayashi 1991). Foraging female Cotesia glomerata (L.) are strongly attracted to cabbage plants with Pieris brassicae (L.) feeding damage (Steinberg et al. 1992). Mitchell and co-workers have observed similar behavioral responses by C. plutellae to cabbage and collard plants infested with different larval pests including diamondback moth, cabbage looper [Trichoplusia ni (Hübner)], and imported cabbageworm [P. rapae (L.)] (unpublished data).

There was a higher consumption of foliage by normal larvae compared with sterile larvae when larvae 
were allowed to pupate. This was attributed to a higher mortality rate among sterile larvae over their entire developmental period.

The distance traversed by diamondback moth larvae from hatch to pupation was not significantly different between the 2 types of larvae under laboratory conditions. Moreover, the survival rate of sterile and normal larvae also was not significantly different. The developmental time for pupation was the same for both sets of larvae. Mortality in the laboratory was due primarily to the $3 \mathrm{rd}$ and 4 th instars spinning down on silk threads and landing in the underlying water trays.

Under field conditions, sterile larvae traversed a shorter distance than normal larvae. Even though developmental time from egg to pupation was similar, there was reduced survivorship of sterile larvae compared with normal larvae. There was high mortality among lst instars of the diamondback moth for both sets of larvae, but this was more pronounced with sterile larvae. It is possible that sterile larvae were less tolerant of the higher temperatures experienced under field conditions than normal larvae. These results corroborate prior work that showed low larval survival rates and reduced egg hatch when parent generations of pink bollworm [Pectinophora gossypiella (Saunders) ], sugarcane borer [Diatraea saccharalis (F.)], and fall armyworm [Spodoptera frugiperda (J. E. Smith) ] were irradiated with sub-sterilizing doses of radiation (LaChance 1985, Arthur et al. 1990, Arthur et al. 1991). The overall low survivorship in the field trial indicates that large numbers of eggs would need to be used to have sufficient numbers of larvae to serve as hosts for C. plutellae.

Foliar damage was confined to a single collard plant under field conditions for both types of larvae while the damage in the laboratory trial covered 2 plants. Thus, there would be virtually no risk of sterile diamondback moth larvae moving from collards planted adjacent to cabbage in the field.

The results demonstrate that percent parasitism is not affected by sterilization of the larvae. Augmentative release can play an important role in biological control programs with collards serving as release sites for diamondback moth larvae and the parasitoid $C$. plutellae. The use of sterile diamondback moth larvae in a biological control program would provide the following 2 benefits: (1) a host for augmentative release of parasitoids, and (2) reduced pest populations through a $\mathrm{F}_{1}$ sterility principle (Carpenter 1993).

\section{References Cited}

Alam, M. M. 1992. Diamondback moth and its natural enemies in Jamaica and some other Caribbean islands, pp. 233-243. In Diamondback moth and other crucifer pests. Proceedings, Second International Workshop. Asian Vegetable Research and Development Center, 10-14 December 1990. Publication 92-368. Shanhua, Tainan, Taiwan.

Arthur, V., J.M.M. Walder, and F. M. Wiendl. 1990. Sugar cane borer control through F-1 sterilization. Acta Agric. Nucleatae Sin. 4: 57-63.
Arthur, V., F. M. Wiendl, J. A. Aguilar, and R. E. Domarco. 1991. Effect of gamma radiation on pupal stage on fall armyworm parent and $\mathrm{F}-\mathrm{l}$ generation reproduction, $\mathrm{p}$. 162. Proceedings of the Final Research Coordination Meeting on Radiation Induced F-1 sterility in Lepidoptera for Area-Wide Control, 9-13 September 1991, Phoenix, AZ. IAEA STI/PUB 929.

Biever, K. D., D. L. Hostetter, and J. R. Kern. 1994. Evolution and implementation of a biological control-IPM system for crucifers: a 24-year case history. Am. Entomol. 40: 103-108.

Burton, R. L., and W. D. Perkins. 1989. Rearing the corn earworm and fall armyworm for maize resistance studies, pp. 337-345. In Towards insect resistant maize for the third world: Proceedings of an International Symposium on the Methodologies for Developing Host Plant Resistance to Maize Insects. CIMMYT, Mexico.

Carpenter, J. E. 1993. Integration of inherited sterility and other pest management strategies for Helicoverpa zea: status and potential, pp. 363-370. In Proceedings of an International Symposium on Management of Insect Pests: Nuclear and Related Molecular and Genetic Techniques. Jointly organized by the International Atomic Energy Agency and The Food and Agriculture Organization of the U.N., Vienna, 19-23 October 1992. IAEA SM-327/35.

Carpenter, J. E., Hidrayani, and W. Sheehan. 1996. Compatibility of $\mathrm{F}_{1}$ sterility and a parasitoid, Cotesia marginiventris (Hymenoptera: Braconidae), for managing Spodoptera exigua (Lepidoptera: Noctuidae): acceptability and suitability of hosts. Fla. Entomol. 79: 289-295.

Dicke, M., and J. Takabayashi. 1991. Specificity of induced indirect defense of plants against herbivores. Redia 17(3): $105-113$.

Dicke, M., M. W. Sabelis, J. Takabayashi, J. Bruin, and M. A. Posthumus. 1990. Plant strategies of manipulating predator-prey interactions through allelochemicals: prospects for application in pest control. J. Chem. Ecol. 16: 30913118.

Guy, R. H., N. C. Leppla, J. R. Rye, C. W. Green, S. L. Barrette, and K. A. Hollien. 1985. Trichoplusia ni, pp. 487-494. In P. Singh and R. T. Moore [eds.], Handbook of insect rearing, vol. 2. Elsevier, Amsterdam.

Hagvar, E. B., and T. Hofsvang. 1991. Aphid parasitoids (Hymenoptera, Aphidiidae): biology, host selection and use in biological control. Biocontrol News Inf. 12: 13-41.

Horn, D. J. 1987. Vegetational background and parasites of larval diamondback moths in collards. Entomol. Exper. et. Appl. 43: 300-303.

Jansson, R. K., and S. H. Lecrone. 1988. Potential of teflubenzuron for diamondback moth (Lepidoptera: Plutellidae) management on cabbage in southern Florida. Fla. Entomol. 71: 605-615.

Knipling, E. F. 1992. Principles of insect parasitism analyzed from new perspectives: practical implication for regulating insect populations by biological means. U.S. Dep. Agric. Agric. Handb. 693: 337.

LaChance, L. E. 1985. Genetic methods for the control of lepidopteran species: status and potential. ARS-28. USDA, Washington, DC.

Lim, G. S. 1986. Biological control of diamondback moth, pp. 159-171. In Diamondback moth management. Proceedings of the First International Workshop. Asian Vegetable Research and Development Center, Shanhua, Taiwan. Shanhua, Tainan, Taiwan

Mahr, S., D. Mahr, and J. Wyman. 1993. Biological control of insect pests of cabbage and other crucifers. N. Cent. Reg. Publ. 471: 54 . 
Mitchell, E. R., F. C. Tingle, R. C. Navasero-Ward, and M. Kehat. 1997. Diamondback moth (Lepidoptera: Plutellidae): parasitism by Cotesia plutellae (Hymenoptera: Braconidae) in cabbage. Fla. Entomol. 80: 477-489.

Miyata, T. H., H. Kiwan, and T. Sato. 1982 . Insecticide resistance in the diamondback moth, Plutella xylostella (L.) (Lepidoptera: Plutellidae). Appl. Entomol. Zool. 17:539 542.

Muckenfuss, A. E., B. M. Shepard, and E. R. Ferrer. 1990. Mating mortality of diamondback moth in coastal South Carolina, pp. 27-36. In Diamondback moth and other crucifer pests, Proceedings, Second International Workshop, 10-14 December 1990, Asian Vegetable Research and Development Center, Tainan, Taiwan. Publ. 92-368. Shanhua, Tainan, Taiwan,

Okine, J. S., E. R. Mitchell, and G. Y. Hu. 1996. Low temperature effect on viability of Diadegma insulare $(\mathrm{Hy}-$ menoptera: Ichneumonidae) pupae and effect of this parasitoid on feeding rate of diamondback moth larvae (Lepidoptera: Plutellidae). Fla. Entomol. 79: 503-509.

Ooi, P.A.C., and K. I. Sudderuddin. 1978. Control of diamondback moth in Cameron Highlands, Malaysia, pp. 214-227. In Proceedings, Plant protection Conference, Malaysian Plant Protection Society, Kuala Lumpur, Malaysia.

Parker, F. D. 1971. Management of pest populations by manipulating densities of both host and parasites through periodic releases, pp. 365-376. In C. B. Huffaker [ed.], Biological control. Plenum, New York.

Ru, N., and R. B. Workman. 1979. Seasonal abundance and parasites of the imported cabbageworm, diamondback moth and cabbage webworm in Northeast Florida. Fla. Entomol. 62: 68-69.

SAS Institute. 1988. SAS/STAT user's guide, release $6.03 \mathrm{ed}$. SAS Institute, Cary, NC.

Shelton, A. M., and J. A. Wyman. 1992. Insecticide resistance of Diamondback moth in North America, pp. 447454. In Diamondback moth and other crucifer pests. Proceedings Second International Workshop. Asian Vegetable Research and Development Center, 10-14 December 1990, Tainan, Taiwan. Publication 92-368. Shanhua, Tainan, Taiwan.

Steinberg, S., M. Dicke, L.E.M. Vet, and R. Wanningen. 1992. Response of the braconid parasitoid Cotesia (Apanteles) glomerata (L.) to volatile infochemicals: effects of bioassay setup, parasitoid age and experience and barometric flux. Entomol. Exp. Appl. 63: 163-175.

Sun, C. H., H. Chi, and H. T. Feng. 1978. Diamondback moth resistance to diazinon and methomyl in Taiwan. J. Econ. Entomol. 71: 551-554.

Sun, C. N., T. K. Wu, J. S. Chen, and W. T. Lee. 1986. Insecticide resistance in the diamondback moth, pp. 359 372. In Diamondback moth management, Proceedings, lst International Workshop, 11-15 March 1985. Asian
Vegetable Research and Development Center, Tainan, Taiwan. Shanhua, Tainan, Taiwan.

Sutrisno, S., and M. Hoedaya. 1993. The sterile insect technique and transmission of inherited sterility to control the diamondback moth, Plutella xylostella (L.), and the cabbage webworm, Crocidolomia binotalis Zell, pp. 395- 403. In Proceedings of an International Symposium on Management of Insect Pests: Nuclear and Related Molecular and Genetic Techniques. Jointly organized by the International Atomic Energy Agency and The Food and Agriculture Organization of the U.N., Vienna, 19-23 October 1992. IAEA SM-327/35.

Tabashnik, B. E. 1994. Evolution of resistance to Bacillus thuringensis. Annu. Rev. Entomol. 39: 47-79.

Tabashnik, B. E., N. L. Cushing, N. Finson, and M. W. Johnson. 1990. Field development of resistance to Bacillus thuringensis in diamondback moth (Lepidoptera: Plutellidae). J. Econ. Entomol. 83: 1671-1676.

Talekar, N. S., S. T. Lee, and S. W. Huang. 1986. Intercropping and modification of irrigation for the control of diamondback moth, pp. 145-152. In Diamondback moth management. Proceedings, lst International Workshop, 11-15 March 1985, Asian Vegetable Research and Development Center, Tainan, Taiwan. Shunhua, Tainan, Taiwan

Talekar, N. S. 1992. Diamondback moth and other crucifer pests. In Proceedings of the Second International Workshop, 10-14 December 1990, Asian Vegetable Research and Development Center, Tainan, Taiwan. Publication 92-368. Shunhua, Taipei, Taiwan.

Talekar, N. S., and A. M. Shelton. 1993. Biology, ecology, and management of diamondback moth. Annu. Rev. Entomol. 38: 275-301.

Turlings, T.C.J., J. H. Tumlinson, and W. J. Lewis. 1990. Exploitation of herbivore-induced plant odors by host seeking parasitic wasps. Science (Wash. D.C.) 250: 12511253.

Turlings, T.C.J., J. H. Tumlinson, and W. J. Lewis. 1991. Isolation and identification of allelochemicals that attract the larval parasitoid, Cotesia marginiventris (Cresson), to the micro-habitat of its hosts. J. Chem. Ecol. 17: 22352251.

Waterhouse, D. F., and K. R. Norris. 1987. Biological control: Pacific prospects. Inkata, Melbourne, Australia.

Wakisaka, S., R. Tsukuda, and F. Nakasuji. 1992. Effects of natural enemies, rainfall, temperature and reproduction of the diamondback moth. In Diamondback moth and other crucifer pests. Proceedings Second International Workshop. Asian Vegetable Research and Development Center, 10-14 December 1990, Tainan, Taiwan. Publication 92-368. Shanhua, Tainan, Taiwan.

Received for publication 6 March 1998; accepted 6 July 1998 